\title{
Characteristics, motivations and experiences of volunteer befrienders for people with mental illness: a systematic review and narrative synthesis
}

\author{
Sarah Toner ${ }^{1}$, Lauren M. Hickling ${ }^{1}$, Mariana Pinto da Costa ${ }^{1,2}$, Megan Cassidy ${ }^{1}$ and Stefan Priebe ${ }^{1 *}$ (D)
}

\begin{abstract}
Background: The literature suggests that many people in the general population tend to distance themselves from those with mental illness. However, there are volunteers that behave differently, spending their free time with people with mental illness and providing direct input in the form of befriending. Whilst there are a range of befriending programmes, little is known about who these volunteer befrienders are, and a previous review of different forms of volunteering in mental health care found data on only 63 befrienders.

Methods: We conducted a systematic electronic search of databases (BNI, CNIL, EMBASE, MEDLINE, PsycINFO, Cochrane Registers, Web of Science) to detect all papers reporting characteristics of befriending volunteers in mental health care published between 2011 and April 2018. The articles retrieved were combined with previous papers identified in an earlier review and with relevant papers identified by experts in the field. The articles that met the inclusion criteria were extracted and narratively synthesised.

Results: Nine studies met the inclusion criteria for this review, reporting characteristics of a total of 577 volunteer befrienders. The most often reported characteristics were age and gender, motivations to volunteer and experience of the role. Whilst characteristics vary greatly, most volunteers are female, and the average age is 50 years. Motivations generally fit into the categories of "giving" and "getting" and experiences are mixed.

Conclusion: Published research on volunteer befrienders has increased in the last eight years, but is still limited. The range of characteristics suggests that there is a potential for encouraging a variety of people to volunteer as befrienders for people with mental illness. Understanding the characteristics and motivations of volunteers may help refine programmes and improve the experience of the volunteer befrienders.
\end{abstract}

Keywords: Review, Befriending, Characteristics, Mental illness, Volunteering, Motivation, Experience

\section{Background}

People with mental illness can often face negative stereotypes, discriminatory behaviour and sometimes even self-stigma [1], and the literature suggests that some people in the general population have a tendency to distance themselves from those with mental illness [2]. Despite this, some people seek direct contact and offer their free time as volunteers to support individuals with mental illness.

\footnotetext{
* Correspondence: s.priebe@qmul.ac.uk

${ }^{1}$ Unit for Social and Community Psychiatry (WHO Collaborating Centre for Mental Health Service Development), Queen Mary University of London, London, UK Full list of author information is available at the end of the article
}

A particular form of volunteering in mental health care is befriending $[3,4]$, where volunteers usually provide repeated, one-to-one and face-to-face contact to develop social relationships with people with mental illness. Some studies reported a reduction of depressive symptoms $[5,6]$ and social isolation [7] in people supported by befrienders. The literature suggests that volunteer befrienders can reap benefits as well, even outside mental health, such as being able to help others, gain experience, or develop a sense of satisfaction from befriending $[8,9]$.

Yet, research on befriending is limited, and little is known about the characteristics of those who volunteer

(c) The Author(s). 2018 Open Access This article is distributed under the terms of the Creative Commons Attribution 4.0 International License (http://creativecommons.org/licenses/by/4.0/), which permits unrestricted use, distribution, and reproduction in any medium, provided you give appropriate credit to the original author(s) and the source, provide a link to the Creative Commons license, and indicate if changes were made. The Creative Commons Public Domain Dedication waiver (http://creativecommons.org/publicdomain/zero/1.0/) applies to the data made available in this article, unless otherwise stated. 
to become befrienders [5]. Such information is crucial for befriending programmes as it is imperative to find, recruit and retain the necessary volunteers.

Motivations of volunteers have been explored previously, for example, as illustrated in the 'Octagon Model' [10], which covers the dimensions of 'giving' versus 'getting,' 'distance' versus 'proximity', 'thought' versus 'action', and 'continuity' versus 'newness' of experience.

In 2012, Hallett et al. [11] published a systematic review of volunteers in mental health care, addressing their characteristics, reasons for volunteering, and experience in the volunteering role (based on a search in November 2010). However, Hallett et al.'s [11] review included all types of volunteering, such as, helping in groups, providing training in educational programmes, and one-off support for events. It found information on a total of 540 volunteers but only 63 of these were befrienders. Hallett et al. [11] identified a generally mixed demographic; however, a large proportion of befrienders were female. Additionally, experiences of befriending were mostly positive, and the motivations of "giving" something to others or "getting" something from the experience were cited commonly for volunteer befrienders.

Against this background, our aim has been to conduct a systematic review to identify the characteristics of volunteer befrienders and to describe their motivations and experiences. We assumed that the literature since the Hallett et al. [11] review would provide more data on which to draw conclusions about who volunteers to befriend people with mental illness.

\section{Methods}

A systematic literature review, in accordance with the Preferred Reporting Items for Systematic Reviews and Meta-analyses (PRISMA) guidelines [12], was used to identify the characteristics of befriender volunteers in mental health. This was combined with a narrative synthesis grounded on the guidelines developed by Popay et al. [13] to describe their motivations and experiences in volunteering.

\section{Search strategy}

We searched the following databases: BNI, CNIL, EMBASE, MEDLINE, PsycINFO, Cochrane Registers, Web of Science (Psychiatry) and grey literature databases. The following search terms were used: volunteer descriptors (Group 1), mental health descriptors (Group 2) and outcome descriptors (Group 3) (Full list of search terms is available as Additional file 1). The results from this search conducted on 11 April 2018 were included.

A secondary hand search was performed in relevant psychiatric journals, grey literature and references, and experts were contacted to identify additional relevant papers in the field.

\section{Eligibility criteria}

The review included primary studies reporting data on volunteer befrienders. Eligibility criteria were: i) participants were unpaid lay/nonprofessional volunteers, ii) the volunteer activity was a regular commitment (e.g. not a 'one-off') with an adult mental health population, iii) the volunteering activity involved only one-to-one, face-toface contacts.

Texts were excluded if they reported information about: i) volunteers that were currently peers, peer workers, family members, paid carers, paid lay workers, mental health professionals or already known friends, ii) the volunteer activity was not specific to a population with severe mental illness (e.g. dementia/substance abuse/HIV/refugees/ cancer volunteering), iii) the volunteering had other formats beyond one-to-one (e.g. groups), face-to-face contact (e.g. telephone helpline/online volunteering), iv) volunteering was part of a course requirement, v) volunteering was a one-off activity (e.g. helping after a natural disaster), vi) the literature was in an inappropriate extraction material (e.g. charity advertising booklet or report).

\section{Data extraction and analysis}

Following the search, all potential studies were exported into EndNote version X5 bibliographic software and duplicates removed. Titles and abstracts were screened for inclusion with a random selection of $20 \%$ of the abstracts being screened by a second assessor. If there was any ambiguity about the study, the full paper was obtained and reviewed by two assessors. Inter-reviewer agreement at the screening stage was $94 \%$. There were no discrepancies relating to those papers selected for inclusion in the full-text search. Data extraction was completed by two assessors. Disagreements regarding full-texts were addressed by discussion and input from a third reviewer.

The following quantitative and qualitative data of the studies were extracted: i) about the studies: year, country, setting, aims, and methods; ii) about volunteers: number, age, gender, education level, employment status, religion, ethnicity, relationship status, living arrangements, motivations, previous experience in mental health volunteering, previous connection to organisation, previous experience as a patient in mental health care, volunteer role, volunteer activities, length of commitment, positive and negative experiences; iii) about the volunteering organisation: type, patient group supported, benefits to people with a mental illness, method of recruiting volunteers, volunteer selection criteria, matching process, volunteer training and supervision.

Narrative synthesis was used to analyse the motivations and experiences of the volunteers. MPC independently conducted the preliminary synthesis based on the extracted findings. By deductively conducting the narrative synthesis, preliminary themes were developed based 
on the hypothetic-deductive approach featured in the literature, with motivations categorised either as 'giving' (doing something for others) or 'getting', (doing something for themselves); and experiences as 'positive' or 'negative'.

These overarching categories were discussed with all members of the team through an iterative process of continuous discussion, critical reflection, reference to the extracted data and feedback, to ensure a range and depth of the materials. Similar concepts were grouped into the most suitable overarching category, and sub-categories were created where relevant. Tabulation and grouping data was used, selecting suitable illustrative quotations.

\section{Results}

The searches yielded a total of 24,655 papers which were then screened. Of these, two met the eligibility criteria. Results were combined with the studies identified in the earlier review [11], and one paper identified by experts that was unpublished at the time, but has been published since. A total of nine studies reporting volunteer befriender characteristics were included. The results of the searches and reasons for exclusion are detailed in Fig. 1.

\section{Overview of the papers}

As shown in Table 1, papers identified in the current review came from five different countries: five from the
UK [14-18], and one each from Austria [19], Germany [20], Ireland [21] and the USA [22] and included a variety of study designs. Two papers did not state how many volunteers were included, and three provided data on fewer than 30 volunteers $[18,20,22]$. Not including the volunteers in the papers where no numbers were provided, we obtained information on a total of $577 \mathrm{vol}$ unteers. Texts were written in English or German.

\section{Volunteering programmes}

The majority of befriending programmes were run by third sector, non-profit organisations [14-20, 22], and one was specifically set up for a randomised controlled trial (RCT) run by an Irish university [21]. Many studies stated that the aim of befriending was to reduce social isolation and promote social activities and inclusion [14, 16, 18].

Six papers mentioned the duration of the befriending relationship. For most programmes, the intended average duration was 12 months with large variations of the actual relationship length $[14,16-18,22]$. One programme requested a nine month commitment from befrienders [21].

Three studies referred to matching befrienders and befriending recipients (hereafter, referred to as befriendees). Sheridan et al. [21] reported that their volunteer befriender cohort completed a profile of demographic characteristics, social life and leisure preferences. This was used to match

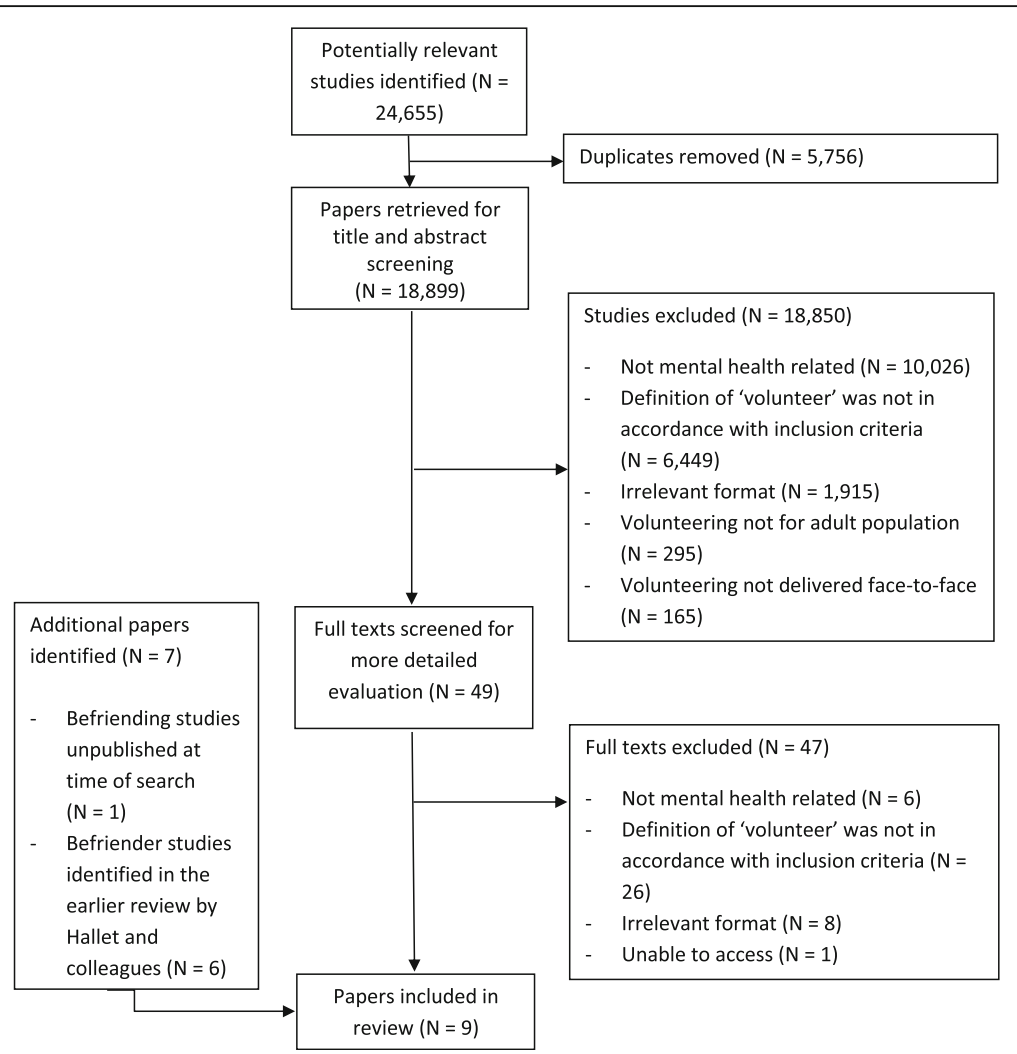

Fig. 1 PRISMA Diagram 


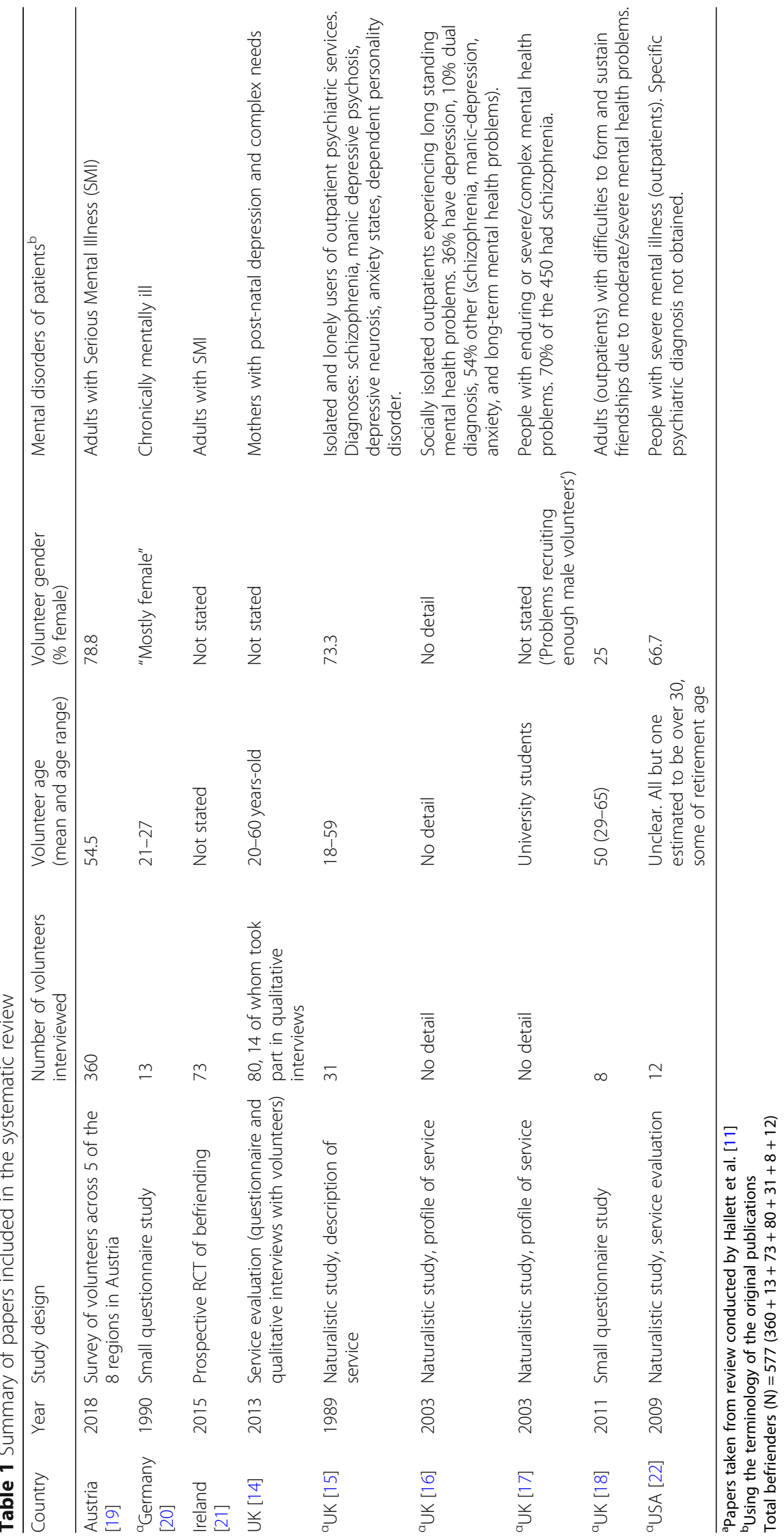


participants based on shared interests. Similar approaches were taken in the remaining two studies $[17,18]$.

Training and supervision of befrienders were outlined in six papers, in which both were described as compulsory [14-18, 22]. This ranged from a one-day programme [21] to six days of training delivered by the project co-ordinator, covering anticipated roles and responsibilities [14]. In another programme befrienders received support during the programme when needed but no initial training [20].

The processes of recruiting befrienders were described in three papers. Sheridan et al. [21] recruited them for their RCT through an "extensive strategy" across a wide range of groups and organisations in the community. Among the remaining studies $[16,17]$, newspaper advertisements were most often used followed by poster displays, word of mouth, local radio adverts, leaflets and student enquiries.

Selection processes for choosing befrienders were discussed by two papers. For the RCT [21], befrienders were selected for participation through an interview process, completion of a police vetting process and two character references for each application. The other study recruited "current psychology undergraduates or graduates who have expressed a desire to do clinical psychology training" [17].

\section{Characteristics of volunteers}

Age

As shown in Table 1, seven papers provided some information on the age of volunteers. Befrienders had a mean of 50 years-old with a very wide range between 18 and 65 years old [14, 15, 18-20, 22].

\section{Gender}

Six of the papers reported the gender of the befrienders. In most papers, the majority of befrienders were female $[15,17,19,20,22]$. Only one study [18] reported a sample with more males (75\%) than females.

\section{Employment status}

Two papers indicated the employment status of the volunteers. One reported that half of volunteers were retired [18] with the remainder either unemployed or in full-time education. Another study reported that all volunteer befrienders were university students [17].

\section{Ethnicity}

The ethnicity of the volunteers was reported in one paper from the United Kingdom. The sample was described as 'mainly White British' [14].

\section{Relationship status}

The relationship status was included in three papers. Two of these found that the majority of volunteers were married or in civil partnerships $[14,19]$. In contrast, the majority (10/13) of volunteers described by Brackhane and colleagues [20] were living alone.

\section{Past psychiatric history}

Two papers gave information about the volunteers' past psychiatric history, reporting that approximately one third of befrienders had personal experience of mental health care $[18,22]$.

\section{Motivations for volunteering}

Four papers $[14,15,17,19]$ reported the motivations of the befrienders in the study (Table 2). Motivations to volunteer were studied by Klug and colleagues [19], using a list of nineteen predefined motivations.

Table 2 Motivations of volunteer befrienders

\begin{tabular}{|c|c|}
\hline Getting & \\
\hline $\begin{array}{l}\text { Tombs et al., } \\
2003[17]\end{array}$ & $\begin{array}{l}\text { "undergraduates and graduates enquiring about } \\
\text { shadowing or unpaid placements in order to gain } \\
\text { experience for clinical training" }\end{array}$ \\
\hline & "to gain assistant and research assistant post" \\
\hline Klug et al., & "Curious to find out if I am suitable for the role" \\
\hline 2018 [19] & "Test out career aspirations" \\
\hline & "Enhance my awareness of mental health issues" \\
\hline & "Befriending looks good on my CV" \\
\hline & $\begin{array}{l}\text { "To gain psychologically relevant experience } \\
\text { (for my career)" }\end{array}$ \\
\hline & "Acquire new skills" \\
\hline & "Meet new people" \\
\hline & "Find explanations for my own behaviour" \\
\hline & "Have close contact with others" \\
\hline & "To feel like a better person" \\
\hline & "To feel needed and acknowledged" \\
\hline & "To be accepted and liked" \\
\hline Giving & \\
\hline $\begin{array}{l}\text { Kingdon et al., } \\
1989 \text { [15] }\end{array}$ & $\begin{array}{l}\text { "a practical way of giving something back after being } \\
\text { helped" }\end{array}$ \\
\hline $\begin{array}{l}\text { Coe et al., } \\
2013[14]\end{array}$ & $\begin{array}{l}\text { "I wanted to give something back to the community } \\
\text { really and I feel that I have done that. Um. It's kind } \\
\text { of made me feel accepted in a way" }\end{array}$ \\
\hline $\begin{array}{l}\text { Klug et al., } \\
2018 \text { [19] }\end{array}$ & $\begin{array}{l}\text { "I have received voluntary help in the past, and wanted } \\
\text { to give something back" }\end{array}$ \\
\hline & "Feel responsibility to help others" \\
\hline & "Helping others is part of my philosophy of life" \\
\hline & "Helping others is part of my religious belief" \\
\hline & "I wanted to do something useful with my spare time" \\
\hline
\end{tabular}


The different reasons and motivations of volunteers were categorised in two main themes, "getting" and "giving", as illustrated in Table 2.

"Giving" These motivations were expressed in four studies [14-16, 19], where volunteers shared a desire to give something back through the programme. Kingdon et al. [15] stated that their befrienders wanted to take part in a befriending programme to give back to the service that they had used previously. Similarly, many volunteers working with mothers with post-natal depression had experienced post-natal depression themselves, and described this as a motivation for volunteering [14]. McGowan et al. [16] reported that volunteer befrienders wanted to "give" something of themselves during their time, although they did not describe more specific examples.

"Getting" Five studies described "getting" as a motivation for volunteers $[14,16,17,19,20]$. Still, what volunteers wanted to get was quite varied, and ranged from: i) 'getting involved with the community' [14], ii) testing out their own suitability for befriending role, iii) finding explanations for their own behaviours [16, 20], iv) testing out potential career aspirations [16, 17], v) learning more about local mental health services, vi) acquiring new skills or vii) meeting new people [16].

\section{Experiences of volunteering}

Volunteers' experiences in the role were discussed in five of the ten papers $[14,17,18,20,22]$. The experiences described by the volunteer befrienders were quite varied, at times positive (Table 3 ) and on other occasions negative (Table 4).

Positive experiences Qualitative interviews from Coe and Barlow [14] portrayed positive experiences of volunteer befrienders, describing ways in which they supported the befriendee, feeling rewarded for contributing to the befriendee's recovery. The positive experience of feeling good about helping someone else was also expressed by eight of 12 volunteers interviewed by McCorkle and colleagues [22]. Some described ways in which volunteering contributed to them personally, such as increasing their self-esteem, confidence and acceptance [14]. Many volunteers felt that with time they gained a genuine friend themselves, wanting to continue the relationship as friends, with many expressing that the benefits of one-to-one volunteering far outweighed the cost in time, money and energy [22].

A positive impact from volunteering on attitudes toward mental illness was discussed in three papers [18, $20,22]$. The experience of volunteering made befrienders reevaluate their preconceptions surrounding mental illness, which they considered a valuable growth opportunity [22]. In some cases this changed previously negative attitudes toward people with mental illness; some lost their initial concerns about the unreliability of people with a mental illness, and found them "surprisingly normal" [20]. For others with personal experience of mental illness, volunteering offered a new perspective on their own problems [18], learning and reflecting about themselves, and instilled a sense that they had benefitted from befriending as much as the befriendee [22].

Negative experiences Negative experiences were described in relation to the behavior of the befriendee in three papers $[18,20,22]$. Some befrienders were left feeling unappreciated [22] when the befriendee did not maintain communication, was often late, or appeared to use the befriender "as a taxicab". Other volunteers expressed difficulties in dealing with confidentiality and privacy, balancing their personal feelings with a sense of professionalism when sensitive information was disclosed by the befriendee [18]. Another matter which was disliked was the recruitment process [17, 21], the bureaucracy (police checks) and waiting (lengthy delays) experiences once recruited, making befrienders drop out of the programme before they had even begun.

\section{Discussion \\ Main findings}

This review provided data on 577 volunteer befrienders from nine studies, around nine times as many befrienders as summarised in a previous review. Yet, more than half of the total number of included befrienders derived from one large study in Austria [19].

The findings suggest that the mean age of befrienders is 50 years-old, but with a very broad range, that they are predominantly female, and that many have experience of psychiatric treatment either themselves or through a close friend or family member. Overall, there was a substantial variation in the socio-demographic characteristics of befrienders between, and also within, studies.

In terms of motivations for befriending, both "giving" something to the befriendee community or in general, and "getting" something out of the programme for themselves appear important.

Positive experiences generally centre around the impact of befriending on the befriendee and own changes in attitudes toward mental illness, while negative experiences related to feeling unappreciated by the befriendee or bad experiences with the befriending organisation. Volunteers had mixed feelings about their relationship with paid mental health professionals and tend to perceive a lack of clarity surrounding their role as a befriender. 
Table 3 Positive experiences of the volunteer befrienders

1.Satisfaction with the relationship with the befriendee

1.1.Spending nice time together

McCorkle et al., "meeting each other's families, dining in each other's 2009 [22] Momes, celebrating holidays together."

"He enjoys getting together. We enjoy each other, getting together and talking, and l've decided that that's of value to me."

1.2.Trusting each other

Mitchell \& Pistrang, 2011

"She seems to be able to talk to me about all sorts [18] of things. Sometimes really personal things... it's a confidential situation, it's not going any further than us. So maybe that's what gives her the freedom to talk."

"While I'm talking to him I'm not constantly thinking of the roles that I'm the befriender and he is the befriendee, we're two people having a chat."

"I'm just myself and he's just himself, we just happen to be doing this particular thing, in this particular relationship, in this particular way. .. It's more important for us just to be ourselves."

McCorkle et al., "We're there for each other."

2009 [22]

1.3. Wanting to continue the relationship as friends

McCorkle et al., "If [the befriending scheme] ended, he and I would 2009 [22] probably still be friends 10 years hence, still doing some stuff together"

"in this movement from "helper/helpee' to true friends"

2. Good experience with the volunteering scheme

2.1.Access to support/supervision

Tombs et al. "the most useful aspect being the provision of supervision 2003 [17] by clinical psychologists and advice about writing application forms"

Mitchell \& "When she was cutting it was really difficult and I was Pistrang, really distressed about it, so I called [befriending 2011 [18] scheme coordinator] to see how to handle it...so it was like dealing with it together. It's not like I'm alone dealing with the situation."

2.2.Usefulness of sharing experiences with other volunteers

McCorkle et al., "It's so nice because other volunteers who've already 2009 [22] gone through it and have found out what works have helped me a lot."

3. Personal gains with the relationship

3.1. Feeling good to provide new experiences to the befriendee

Mitchell \& "to get out and visit places and do things that otherwise Pistrang, [befriendee] wouldn't have done naturally on his own, 2011 [18] and that's an exposure to a whole load of different things...it's opening that window of things out there."

"about creating opportunities for [befriendee] to go where perhaps he wouldn't have gone before in relationships."

3.2. Filling their own free time

McCorkle et al., " "filling the gap created by retirement." 2009 [22]
Table 3 Positive experiences of the volunteer befrienders (Continued)

3.3. Feeling rewarded for contributing to the befriendee's recovery

McCorkle et al., "No matter how much time, or lost sleep, or stress you 2009 [22] feel the investment requires, the satisfaction of being intimately involved with another life in recovery is just extraordinarily self-enhancing, reinforcing."

"I feel good about myself that l've been able to do something for him."

Coe et al., "But I remember this particular girl the first time I met 2013 [14] her she just ... I could tell by her eyes what pain she was in. She just had ... she sort of glared at me. And now she does actually look happy again and there is that sparkle in her eyes."

"It's just really ... I just found it really rewarding. I wanted to give something back to the community really and I feel that I have done that. Um. It's kind of made me feel accepted in a way."

3.4. Being supported by the befriendee

McCorkle et al., "I like it that she's been there even for me, when 2009 [22] needed someone to lean on, that I could talk to her."

3.5. Learning/reflecting about themselves

McCorkle et al., " "required dealing with one's own negative 2009 [22] $\quad$ preconceptions about mental illness."

Mitchell \& "...it's part of that looking at whatever the situation is, Pistrang, from a lot of different perspectives... You look at it in a 2011 [18] balanced type of way, rather than in one fixed way."

"It makes me think about me, who I am...you do have to say to yourself, 'Am I happy with where I am?', and if there are things that are getting to me where is that layer occurring and you know, because I do become more conscious."

"It helps you reassess some of the things that have happened to yourself, and how other people may have reacted or looked at it."

3.6. Changing attitudes towards people with mental disorders

Mitchell \&

Pistrang, 2011

"... It's nice to sort of confirm that what you read in

[18]

4. Professional gains with the experience

4.1. Having contact with people with mental disorders

Mitchell \& "I don't know anyone with a diagnosed mental Pistrang, 2011 disorder so I had no idea what someone like that [18] would be like."

4.2. Helping to clarify their career path

Tombs et al., "it has also been useful in clarifying whether clinical 2003 [17] psychology is the career."

4.3. Helping to build the CV

Tombs et al., "[helped with the] demand for relevant voluntary 2003 [17] experience whilst competition for assistants' posts remains high and most posts require some previous client experience."

\section{Strengths and limitations}

To our knowledge, this is the first systematic review focusing on the characteristics, motivations and experiences of befrienders in mental health care. It provides a 
Table 4 Negative experiences of the volunteer befrienders

\begin{tabular}{|c|c|}
\hline \multicolumn{2}{|c|}{ 1. Bad experience with the volunteering schemes } \\
\hline \multicolumn{2}{|c|}{ 1.1.Bureaucracy/waiting when recruited } \\
\hline $\begin{array}{l}\text { Tombs et al., } \\
2003 \text { [17] }\end{array}$ & $\begin{array}{l}\text { "the increase in delays in registering befrienders might } \\
\text { well have a negative impact on recruitment as } \\
\text { volunteers may need to wait for up to six months } \\
\text { before being allocated a client." }\end{array}$ \\
\hline & $\begin{array}{l}\text { "waiting three months for clearance to proceed and, } \\
\text { regrettably ... may have to wait several months } \\
\text { more." }\end{array}$ \\
\hline
\end{tabular}

1.2.The costs linked with the activities
Tombs et al., "volunteers are expected to pay for their own 2003 [17] refreshments and entertainment."
McCorkle et al., "insisted on full equality of financial contribution and 2009 [22] decision making so that the [befriending] relationship did not encourage passivity and dependency."

1.3. Feeling pressured with the commitment to meet

Brackhane et "tension between free voluntary input and a sense of al., 1990 [20] duty or obligation"

McCorkle et al., "after a rough day at work, meeting could feel more 2009 [22] like a commitment than like fun."

2.Dissatisfaction with the relationship with their befriendee

2.1.Expectations of their befriendee not being met

McCorkle et al., "expected a client who was much younger, physically 2009 [22] active, and interested in going places and doing things, but ended up with a middle-aged client without those interests."

2.2.Disliking their befriendee

Tombs et al., "Declined befriending ... because they did not like the 2003 [17] potential befrienders on offer"

McCorkle et al., "Then I got to thinking, not every match is going to 2009 [22] Succeed and go off and go to college."

2.3.Difficult to empathise with the befriendee

Mitchell \& "Some of it I can empathise with and some of it I've Pistrang, 2011 absolutely no idea at all...I don't think you will ever [18] get a hundred percent fit with other people... And if you did have that hundred percent fit, it might be ideally the wrong person for them because they'll just wallow in it with them."

3. Challenges in the relationship

3.1.Difficulties in adopting an attentive/supportive role as a volunteer

Brackhane et "avoided emotional talks because of anxiety to get too al., 1990 [20] much worked up about it"

Mitchell \& "I'd say the hardest thing is not giving a true reaction Pistrang, 2011 to the things she says, and biting my lip rather than [18] making or voicing my judgments or opinions..."

"I'm keeping a watchful eye, but not making it obvious"

3.2.Difficulties in setting boundaries

Mitchell \&

Pistrang, 2011

"It's more to do with where I'm putting my boundaries...

[18] about me... The unequal-ness of the relationship is that one. It's not about me."

3.3.Difficulties in dealing with confidentiality/privacy

McCorkle et al., "the awkwardness of running into a friend or business 2009 [22] acquaintance when with one's match."
Table 4 Negative experiences of the volunteer befrienders (Continued)

3.4.Difficulties in tolerating the befriendee's behaviour

McCorkle et al., "[tolerating] heavy smoking and coffee consumption, 2009 [22] occasional outbursts of anger."

3.5.Feeling exploited by the befriendee

McCorkle et al., "There was no joy in it for me by going and picking 2009 [22] $\quad$ her up and taking her to whatever store she wanted to go to. I knew I wouldn't last like that. So I started setting limits and explaining to her that that's not what friends do. They do that occasionally, maybe, but that isn't what a friend does."

"feeling treated as a taxicab was an unpleasant experience."

3.6.Difficulties in ending the relationship

McCorkle et al., "...He's as far as he's gonna be, I think, but I still can't 2009 [22] leave him, 'cause I feel like we've just developed a bond!"

"I can't imagine not having my [befriendee] friend in my life. I really can't"

"worried about what would happen if life changes (such as moving elsewhere for graduate school) prevented continuation of the relationship."

Mitchell \& "I feel like it's slightly kind of a bit like a taboo subject Pistrang, 2011 [the end of the relationship]. Um, I think I would be [18] Scared of saying the wrong thing, if it came up."

summary of the different motivations and experiences of befriender volunteers that appear plausible and are in line with previous literature on volunteering. It covers a significant number of befrienders, but also a range of countries, and languages (English and German) exceeding those in a previous wider review on different types of volunteering in mental health care [11]. A further strength is that to reduce the publication bias, unpublished literature and hand searches of relevant journals were performed to maximise the search. In addition, the themes of the narrative synthesis were identified across a diversity of papers and were discussed within the multidisciplinary team of the co-authors to reduce bias of findings.

The study, however, has several limitations. First, whilst the total number of 577 included befrienders may allow more general conclusions than previously possible, it is still small in the light of the wide use of befriending schemes in some countries, particularly considering that data on 360 befrienders were from only one large survey [19]. Secondly, all papers are from a limited number of high-income countries, and there remains a lack of information about what types of befriending programmes, if any, exist in other countries and what the characteristics of the befrienders in those programmes are. Thirdly, although it was possible to extract some qualitative data about the motivations and experiences of volunteers, papers included only a few quotations, and hence the available data was limited to conduct the narrative synthesis. Fourthly, the quantitative data extracted for this review 
were not consistently reported, which makes it difficult to synthesise the data and compare studies. Finally, with respect to experiences, one may assume that most studies were biased through the selection of interviewees. Befrienders with very negative experiences are more likely to end their befriending sooner and avoid participation in research interviews than those who liked their befriending role and did it for longer.

\section{Comparison with the literature}

Whilst the earlier wider review [11] identified details on only 63 volunteer befrienders, this review found reports on an additional 514 befrienders. Given that the previous review covered the whole period of time since the inception of the included databases and this one added only eight years, the increase of research data on befrienders may reflect a rising research interest in befriending programmes.

The findings here are consistent with those reported by Hallett and colleagues [11]. This is in regards to the predominance of women among befrienders, the otherwise wide range of socio-demographic characteristics, the mix of motivations of "giving" and "getting" for volunteer befrienders, and the mostly positive but still mixed experiences of befrienders.

The categorisation of motivations into "giving" and "getting" reflects one of the four dimensions of the 'Octagon Model' which has been used to describe the motivations of volunteers in general [10]. Klug and colleagues [19] applied such categorisations in their assessment of volunteer motivations. They identified four subgroups of befrienders based on their characteristics (age, gender, marital status and employment status), which were associated with different motivations to engage in befriending. The largest subgroup included married, retired females (median age $=64$ ), which were largely motivated by their responsibility to help others. This motivation was also predominant in two other subgroups, comprised of married retired males (median age $=58$ ), and married females in full-time employment (median age $=51$ ). The final subgroup consisted of single females in full-time employment (median age $=44$ ). The most frequent motivations in the four groups were similar and included aspects of both 'giving' and 'getting'. Only the fourth and youngest group differed in some aspects from the other groups and stated more often the wish to acquire new skills and career aspirations as motivations. It remains unclear to what extent different subgroups of befrienders may respond to different recruitment strategies and benefit from different types of programmes and supervision.

\section{Implications}

The fact that there is a wide variation in the characteristics of volunteer befrienders, including employment and relationship status, suggests that a typical volunteer befriender does not exist and that there is a potential to recruit volunteers for befriending programmes from very different groups in the population. The majority of befrienders being female might reflect gender differences in attitudes, social roles or both. The motivations of different groups and their potentials to engage in specific befriending programmes are likely to vary, and more research is required to tailor recruitment strategies and programmes for people with different backgrounds, interests and social situations. In particular, additional qualitative research should be conducted to further explore the motivations and experiences of different volunteers. Studies with sufficiently large samples should allow the exploration of potentially relevant subgroups, of which only one study has been able to do so far [19].

Allowing volunteering opportunities that are consistent with volunteers' motivations may improve volunteers' satisfaction and retention in these programmes. Equally, exploring the experiences in more detail may help with designing programmes that maximise the satisfaction of befrienders and encourage them to stay in programmes or volunteer again if they had engaged previously and since ceased participating.

Whilst this review summarised data of research publications, this is still limited and inconsistently reported. Therefore, in the future, data about volunteers should be routinely collected and published on a large scale to map out and further develop befriending programmes. This is currently hindered by a number of factors, one of which being that many programmes are run outside mainstream health services with less developed data documentation systems.

\section{Conclusions}

The results reported in this review suggest an increased attention to befriending programmes in research over the last eight years. Apart from most befrienders being female, the variability of characteristics of befrienders suggests that generalised conclusions are difficult. At the same time, it may underline the wide potential to establish more befriending programmes in different contexts, whilst the different motivations and experiences of befrienders point to possibilities for refining and specifying programmes for different types of befrienders.

\section{Additional file}

Additional file 1: Characteristics, motivations and experiences of volunteer befrienders for people with mental illness: A systematic review and narrative synthesis. (DOCX $22 \mathrm{~kb}$ )

Abbreviations

NHS: National Health Service; NIHR: National Institute of Health Research; PRISMA: Preferred Reporting Items for Systematic Reviews and MetaAnalyses; RCT: Randomised Controlled Trial; SMI: Serious Mental Illness 


\section{Acknowledgements}

The authors wish to acknowledge the researchers at the Unit for Social and Community Psychiatry, who provided feedback on an early draft of this paper.

\section{Funding}

This paper presents independent research funded by the National Institute for Health Research (NIHR) under its Programme Grants for Applied Research Programme (Reference Number RP-PG-0611-20002). The funding body was not involved in, and did not influence, the design of the study, data collection analysis or interpretation of the data. The views expressed are those of the author(s) and not necessarily those of the National Health Service (NHS), the $\mathrm{NIHR}$ or the Department of Health.

\section{Availability of data and materials}

Not applicable.

\section{Authors' contributions}

SP developed the study idea and designed the study. ST completed the ful search and data extraction. LH and MC completed a check and extraction from a proportion of the search results. SP reviewed any discrepancies. MPC conducted the narrative synthesis. ST, SP, LH, MC and MPC drafted the manuscript; all authors commented on and agreed to the final manuscript.

\section{Ethics approval and consent to participate}

Not applicable.

\section{Consent for publication}

Not applicable.

\section{Competing interests}

The authors declare that they have no competing interests.

\section{Publisher's Note}

Springer Nature remains neutral with regard to jurisdictional claims in published maps and institutional affiliations.

\section{Author details}

'Unit for Social and Community Psychiatry (WHO Collaborating Centre for Mental Health Service Development), Queen Mary University of London, London, UK. Institute of Biomedical Sciences Abel Salazar (ICBAS), University of Porto, Porto, Portugal.

Received: 8 August 2018 Accepted: 19 November 2018

Published online: 04 December 2018

\section{References}

1. Livingstone J, Boyd J. Correlates and consequences of internalized stigma for people living with mental illness: a systematic review and meta-analysis. Soc Sci Med. 2010;71(12):2150-61.

2. Angermeyer M, Dietrich S. Public beliefs about and attitudes towards people with mental illness: a review of population studies. Acta Psychiatra Scand. 2006;113(3):163-79.

3. Thompson R, Valenti E, Siette J, Priebe S. To befriend or to be a friend: a systematic review of the meaning and practice of "befriending" in mental health care. J Ment Health. 2015;25:71-7.

4. Priebe S, Pavlickova H, Eldridge S, Golden E, McCrone P, Ockenden N, et al. Effectiveness of one-to-one volunteer support for patients with psychosis: protocol of a randomised controlled trial. BMJ Open. 2016;6(8):e011582.

5. Mead N, Lester H, Chew-Graham C, Gask L, Bower P. Effects of befriending on depressive symptoms and distress: systematic review and meta-analysis. Br J Psychiatry. 2010;196(2):96-101.

6. Siette J, Cassidy M. S P. effectiveness of befriending interventions: a systematic review and meta-analysis. BMJ Open. 2017;7:e014304.

7. Mulvihill J. The unique and valuable support provided by mentoring and befriending. Work with Older People. 2011;15(1):34-7.

8. Greenwood D, Gordon C, Pavlou C, Bolton J. Paradoxical and powerful: volunteers' experiences of befriending people with dementia. Dementia. 2018;17(7):821-39.

9. Heslop P, Robinson C. Befriending-more than just finding friends; 2004.

10. Yeung $A$. The octagon model of volunteer motivation: results of a phenomenological analysis. Volunt Int J Volunt Nonprofit Organ. 2004;15(1):21-46.
11. Hallett C, Klug G, Lauber C, Priebe S. Volunteering in the care of people with severe mental illness:a systematic review. BMC Psychiatry. 2012;12:226.

12. Moher D, Liberati A, Tetzlaff J, Altman D, Group P. Preferred reporting items for systematic reviews and meta-analyses: the PRISMA statement. PLoS Med. 2009:6:e1000097.

13. Popay J, Roberts H, Snowden A, Petticrew M, Arai L, Rodgers M, et al. Guidance on the conduct of narrative synthesis in systematic reviews. A product from the ESRC methods Programme. Lancaster: Lancaster University; 2006

14. Coe C, Barlow J. Supporting women with perinatal mental health problems: the role of the voluntary sector. Community Pract. 2013;86(2):23-7.

15. Kingdon D, Turkington D, Collis J, Judd M. Befriending: cost-effective community care. Psychiatr Bull. 1989;13(7):350-1.

16. McGowan B, Jowett C. Promoting positive mental health through befriending. Int J Ment Heal Promot. 2003;5(2):12-24.

17. Tombs D, Stowers C, Fairbank S, Arkill T. A befriending service for individuals with complex, enduring mental health problems. Clin Psychol, BPS Mon Div. 2003;28:33-6.

18. Mitchell G, Pistrang N. Befriending for mental health problems: processes of helping. Psychol Psychother Theory Res Pr. 2011;84(2):151-69.

19. Klug G, Toner S, Fabisch K, Priebe S. Characteristics and motivations of volunteers providing one-to-one support for people with mental illness: a survey in Austria. Soc Psychiatry Psychiatr Epidemiol; 2018:53:841-7.

20. Brackhane R, Strehl C, Wurzer I. Lay help in rehabilitation of psychiatrically handicapped patients-report of two comparative empirical studies. Rehabil. 1990;29(4):254-60.

21. Sheridan A, Drennan J, Coughlan B, O'Keeffe D, Frazer K, Kemple M, et al. Improving social functioning and reducing social isolation and loneliness among people with enduring mental illness: report of a randomised controlled trial of supported socialisation. Int J Soc Psychiatry. 2015;61(3):241-50.

22. McCorkle B, Dunn E, Yu Mui W, Gagne C. Compeer friends: a qualitative study of a volunteer friendship programme for people with serious mental illness. Int J Soc Psychiatr. 2009:55(4):291-305.

Ready to submit your research? Choose BMC and benefit from

- fast, convenient online submission

- thorough peer review by experienced researchers in your field

- rapid publication on acceptance

- support for research data, including large and complex data types

- gold Open Access which fosters wider collaboration and increased citations

- maximum visibility for your research: over $100 \mathrm{M}$ website views per year

At BMC, research is always in progress.

Learn more biomedcentral.com/submission 